\title{
Capsaicin-Sensitive Nociceptive Innervation of the Dura Mater: Implica- tions for the Pathomechanism of Headache
}

\author{
Mária Dux*, Judit Rosta and Gábor Jancsó
}

Department of Physiology, University of Szeged, Hungary

\begin{abstract}
This review focuses on the critical pathophysiological significance of capsaicin-sensitive trigeminal primary afferent neurons in the mechanisms of neurovascular responses in animal models of cranial pain and their possible relevance for primary headaches. In the rat dura mater, neurogenic sensory vasodilator responses elicited by activation of the transient receptor potential vanilloid type 1 (TRPV1) receptor are mediated by the release of calcitonin gene-related peptide (CGRP) from sensory nerves, which suggests that similar mechanisms may operate in man during migraine attacks, when an increased concentration of CGRP is measured in the jugular venous blood. Capsaicin-sensitive trigeminal afferent nerves also contribute to the vasodilatory responses induced by the activation of protease-activated receptor 2 (PAR-2), which involves the release of CGRP from capsaicin-sensitive afferent nerves. Importantly, the activation of PAR-2 has been shown to sensitize the TRPV1 receptor. Demonstration of the colocalization of PAR-2 and TRPV1 receptors in the meningeal axons lends further support to this mechanism. Neurogenic vasodilatory responses mediated by capsaicinsensitive afferent nerves may serve a protective function via the elimination of inflammatory mediators from the tissue, a mechanism which may play a role in the resolution of headaches. Pathological conditions such as diabetes mellitus may compromise this protective mechanism through decreases in the expression of TRPV1 and the release of CGRP. These observations indicate an important role of capsaicin-sensitive meningeal afferent nerves in the pathophysiology of headaches and suggest that pharmacological manipulation of the TRPV1 receptor may offer a promising approach to the management of headaches.
\end{abstract}

Keywords: Calcitonin gene-related peptide, capsaicin, headache, meningeal blood flow, nociception, transient receptor potential vanilloid type 1 receptor.

Despite the many years of research and the availability of clinically effective drugs for headache therapy, the pathogenetic mechanisms of primary headaches are still unclear. Although current opinion holds that migraine attacks start in the brain, clinical and experimental evidence indicates that the headache phase begins with the activation of peripheral nociceptors [1-3]. As the major pain-sensitive intracranial structure, the dura mater encephali has become the preferential target of studies on the peripheral mechanisms of meningeal nociception and headache. It is innervated by trigeminal sensory nerve fibers which contain vasoactive neuropeptides such as calcitonin gene-related peptide (CGRP), substance P (SP) and neurokinin A (NKA) [4-6]. Most of these peptidergic nerve fibers are closely associated with blood vessels and comprise the trigeminovascular system of the meninges [5, 7]. Recent studies indicate that both vascular and neural mechanisms may activate trigeminal perivascular afferent nerves. Once activated, trigeminal afferents convey nociceptive information to the central nervous system (CNS) and, through the release of vasoactive peptides from their peripheral terminals, they also promote a sterile neurogenic inflammatory process in the tissue [8]. Meningeal neurogenic inflammation has been proposed as an important mechanism in the generation of pain and changes in meningeal blood flow in headache patients [9]. Clinical observations support

*Address correspondence to this author at the Department of Physiology, University of Szeged, Dóm tér 10, H-6720 Szeged, Hungary; Tel: 00-36-62545374; Fax: 00-36-62-545842; E-mail: dux@phys.szote.u-szeged.hu the significance of neuropeptide release in the pathophysiology of primary headaches. Blood collected from the jugular vein on the affected side during migraine and cluster headache attacks contains increased levels of the vasodilator neuropeptide CGRP [10, 11]. The activation of chemo/capsaicin-sensitive primary sensory neurons expressing the transient receptor potential vanilloid type 1 (TRPV1) receptors plays a fundamental role in the generation of the neurogenic inflammatory response of the dura mater [12]. For studies of the mechanisms of trigeminal nociceptor activation and changes in dural blood flow, experimental animal models of meningeal nociception have been developed.

In this review, we focus on evidence supporting the pivotal role of trigeminal paravascular chemosensitive nociceptors, which express the TRPV1 receptors, in nociceptive and vascular processes relevant to the pathomechanisms of headaches. In different organs, chemosensitive nerve fibers play a key role in the transmission/modulation of pain elicited by noxious heat, acidic $\mathrm{pH}$ or inflammatory mediators [13-18]. Activation of capsaicin-sensitive nerves may also play a central role in headache mechanisms. Since neurovascular responses are considered to be significant pathophysiological processes involved in the generation, maintenance and/or relief of headache pain, recognition of the physiological role of meningeal capsaicin-sensitive nerve fibers and clarification of the factors and pathophysiological conditions that alter the function or sensitivity of these nociceptive nerves may provide a suitable approach to an understanding of the pathophysiology of primary and other types of headaches. To 
evaluate the possible significance of chemosensitive nociceptive afferents in the generation, maintenance and relief of headache pain, we will discuss the evidence for 1) the existence of chemosensitive nerves in the dura mater, 2) the activation of these nerves by capsaicin and other vanilloids, and 3 ) vascular reactions mediated by the activation of TRPV1, protease-activated receptor 2 (PAR-2) and histamine receptors.

\section{CAPSAICIN-SENSITIVE SENSORY NERVE FI- BERS IN THE DURA MATER ENCEPHALI AND THEIR PATHOPHYSIOLOGICAL SIGNIFICANCE}

\section{Activation of Chemosensitive Primary Sensory Neu- rons Participate in the Central Transmission of Head- ache Pain}

In consequence of the morphological and functional similarities shared by the human and rodent dura mater encephali, the rat dura mater is a suitable animal model for study of the pathophysiological mechanisms of headaches. The blood supply of the rat dura mater is provided by the middle meningeal artery. The dura mater is richly innervated by myelinated (A type) and unmyelinated ( $\mathrm{C}$ type) nerve fibers. The number of $\mathrm{C}$-fibers with a putative nociceptor function is approximately three times that of the A-fibers [19]. Immunohistochemical investigations have identified two different types of nerve plexuses with regard to their localization in the rat dura mater [20]. One plexus was found to be situated within the dural connective tissue, and the other in the perivascular region. The terminals of meningeal afferent A- and C-fibers are unencapsulated free nerve endings [5, 19]. Innervation of the meningeal tissue has three sources; most nerve fibers have a sympathetic or afferent origin, while parasympathetic nerves in the dura mater are rare.

Although all three divisions (ophthalmic, maxillary and mandibular) of the trigeminal nerve contribute to the sensory innervation of the dura mater, the cell bodies supplying the supratentorial part of the dura mater are located in the ophthalmic division of the trigeminal ganglion. Recent studies in our laboratory have revealed that a significant population of the meningeal sensory nerves is capsaicin-sensitive [12]. Capsaicin-sensitive primary sensory neurons comprise a morphologically, neurochemically and functionally wellcharacterized population of sensory ganglion cells [21-23] which express the TRPV1 receptor $[18,24]$. A huge body of evidence indicates that capsaicin-sensitive sensory ganglion neurons participate in the transmission of chemogenic and inflammatory pain $[22,25]$ and through the release of vasoactive peptides (CGRP, SP and NKA) from their peripheral terminals they also play a fundamental role in local regulatory functions of the innervated tissue, including vasodilatation and plasma extravasation [26]. Electron microscopic and immunohistochemical studies have demonstrated the existence of functional capsaicin-sensitive nerves in the rat dura mater $[12,27]$. A rich TRPV1-immunoreactive innervation of the dura mater has been revealed, with the nerve fibers forming bundles or running as single axons in the dural connective tissue and in a paravascular localization along blood vessels. During the past few years, experimental results published by several other research groups have confirmed our findings and extended our knowledge on the morphology and function of meningeal nerves which express the TRPV1 receptor [28-30].

Pathophysiological events leading to the sensitization of meningeal chemosensitive nerves (peripheral sensitization) may be responsible for the intracranial hypersensitivity observed in migraine and other types of headaches; otherwise innocuous stimuli or even pulsatile changes in meningeal blood flow and/or intracranial pressure may activate the trigeminal nociceptive pathway [31]. Prolonged activation of the primary sensory neurons may also alter the excitability of second-order neurons in the caudal trigeminal nuclear complex leading to central sensitization which, in turn, increases the intensity of pain transmission [32].

\section{Activation of Chemosensitive Primary Sensory Neu- rons Induces Vascular Reactions in the Dura Mater}

The activation of capsaicin-sensitive meningeal afferents produces TRPV1 receptor-mediated vasodilatory responses through the release of CGRP in the rat dura mater [12]. In an open cranial window preparation, topical application of capsaicin onto the dura mater induces dose-dependent changes in meningeal blood flow. Chemical stimulation of the meningeal sensory nerve fibers with capsaicin in low concentrations (50-100 $\mathrm{nM}$ ) elicits moderate but significant vasodilatory responses, as assessed by laser Doppler flowmetry. Capsaicin-induced vasoconstriction observed by topical application of capsaicin in higher concentrations is generally regarded as resulting from a direct vascular action of capsaicin independent of neural activation [33, 34]. Vasodilator responses to capsaicin are inhibited or even completely abolished by systemic pretreatment of the animals with capsaicin in a dose that results in a profound depletion of sensory neuropeptides [22, 35-37]. These findings suggest that sensory nerve-mediated vasodilatation in the dura mater involves capsaicin-sensitive afferents. This is supported by findings demonstrating that capsaicin-induced vasodilatation is significantly inhibited by local pretreatment of the dura mater with a TRPV1 receptor antagonist, capsazepine and the CGRP receptor antagonist $\mathrm{CGRP}_{8-37}$. Activation of the nociceptive pathway and meningeal vasodilatation mediated by CGRP appear to be important mechanisms in the pathophysiology of primary headaches. Studies in migraineurs have lent support to this by indicating increased levels of CGRP in the jugular venous blood during headache attacks $[11,38]$. Blockade of the CGRP receptors with non-peptide CGRP receptor antagonists has proved to be a very promising option for the treatment of primary headaches in clinical trials [39]. Although vasodilatation may not be significantly implicated in the generation of pain in meningeal painsensitive structures [40], changes in meningeal blood flow are implicated in the pathophysiology of headaches. Importantly, the accumulation of algogenic and vasoactive agents during headache attacks may impede meningeal tissue integrity $[41,42]$. Neurogenic sensory vasodilatation which develops concommitantly with the activation of meningeal chemosensitive nociceptive fibres may serve a homeostatic function in the dura mater. An increase in blood flow may exert a beneficial effect by removing inflammatory metabolites which induce or aggravate headache attacks [43]. Pharmacological interventions through drugs which proved to be effective in headache therapy may interfere with the physio- 
logical defence mechanism conferred by neurogenic sensory vasodilatation. However, drugs such as triptans, CGRP- and TRPV1 receptor antagonists may produce effective pain relief by reducing transmitter release from the central terminals of nociceptive trigeminovascular nerves.

The pathophysiological significance of plasma extravasation, another component of neurogenic inflammation, is more controversial in the meningeal tissue. In rats, the level of dural plasma extravasation was increased after systemic administration of capsaicin or electrical stimulation of the trigeminal ganglion, and this increase was abolished by neonatal capsaicin treatment [44]. Although some clinical studies have indicated increased contents of plasma SP and CGRP even during headache-free periods in migraineurs [45], clinical trials involving the treatment of patients with the SP antagonist RPR100893 during migraine attacks proved completely ineffective [46]. These clinical and experimental observations indicate that the increase in vascular permeability induced by the release of SP from the stimulated trigeminal sensory nerves is probably not of major significance as regards the pathophysiology of headaches.

\section{Role of Histamine in the Neural and Vascular Reac- tions of the Dura Mater}

In the dura mater, similarly as in other tissues, the activation of capsaicin-sensitive afferent nerves results in the release of vasodilator neuropeptides [47-49]. Besides their direct vascular effects, CGRP and SP released from stimulated nerves initiate a cascade of events that result in the degranulation of mast cells and the activation of platelets. Mast cells containing vasoactive substances have been observed in close proximity to SP-containing nerve fibers. Electrical stimulation of the trigeminal ganglion leads to mast cell activation and degranulation in the dura mater [48]. SP and CGRP release histamine from rat dural mast cells, which suggests an additional pathway for the possible involvement of these neuropeptides in intracranial vasoregulation and neurogenic inflammation, besides their direct effects on blood vessels [50].

The vascular effects of histamine in the dura mater are mediated by the $\mathrm{H}_{1}$ and $\mathrm{H}_{2}$ receptors of arterial vessels. While $\mathrm{H}_{2}$ receptors on smooth muscle cells mediate vasodilatation, the activation of smooth muscle $\mathrm{H}_{1}$ receptors causes vasoconstriction. The vasodilatory effect of $\mathrm{H}_{2}$ receptors predominates when histamine is applied locally onto the dura mater, i.e. when its concentration is high in the perivascular compartment, where the mast cells are located. In contrast, high histamine levels in the blood stream activate endothelial $\mathrm{H}_{1}$ receptors which promote endothelial nitric oxide synthase (NOS) activity to produce nitric oxide (NO), which diffuses to the smooth muscle cells and causes vasorelaxation $[51,52]$.

The communication between sensory nerve endings and mast cells is bidirectional in most tissues. Sensory nerve terminals may be sensitized or even activated by histamine $[53,54]$. Histamine-induced neuropeptide release can be modified by presynaptic $\mathrm{H}_{3}$ receptors present on sensory nerve endings. In the dura mater, the bidirectional communication between these structures has not yet been proved; in an in vitro dura mater preparation, CGRP stimulated the re- lease of histamine, while, reciprocally, histamine was not able to release CGRP from meningeal afferents even under the blockade of presynaptic $\mathrm{H}_{3}$ receptors $[55,56]$.

Although the release of histamine from activated mast cells and the consequent activation of peptidergic nociceptive nerve endings are significant components of neurogenic inflammation in the dura mater, the role of histamine in the pathophysiology of headaches is still a subject of considerable debate. The experimental headache induced by the i.v. infusion of histamine is in many ways similar to the pulsating headache seen in migraine. Moreover, migraine patients seem to be more susceptible than controls to histamineinduced headache [57]. Hence, antihistamines combined with other antiinflammatory medications are recommended in certain forms of headaches; as examples, measures to prevent cluster headache and other headaches combined with allergic reactions include antihistamine therapy, but antihistamines fail to alleviate pain during headache attacks [58, 59].

\section{Activation of the Trigeminal-Parasympathetic Reflex}

Experimental findings have provided evidence of a neural basis for a trigeminal-parasympathetic reflex which explains meningeal vasodilatation during headaches and links increased neurometabolic activity with the transmission of headache pain by the trigeminal nerve [60]: an increase in cortical metabolic activity results in the release of neurotransmitters and metabolites into the extracellular and perivascular spaces. Experimentally induced cortical spreading depression (CSD) which is regarded as an equivalent of the aura phase of migraine attack, is a condition that influences both neuronal activity and blood flow [61]. Neurotransmitters and metabolites released by CSD activate or sensitize perivascular trigeminal afferents and transmit impulses centrally to the trigeminal nucleus caudalis (TNC). Activation of the TNC also leads to stimulation of the superior salivatory nucleus and consequently parasympathetic efferents via the sphenopalatine ganglion. The activation of postganglionic parasympathetic fibers promotes meningeal vasodilatation by releasing vasoactive agents from their terminals, such as vasoactive intestinal polypeptide, NO or acetylcholine [60]. Capsaicin-sensitive trigeminal nerves may be sensitized by inflammatory mediators and tissue metabolites and this might form the structural basis of the trigeminal-parasympathetic reflex whose activation results in the transmission of nociceptive stimuli and promotes parasympathetic meningeal vasodilatation.

\section{Neuron-glia Signaling in the Trigeminal Ganglion}

Migraine attack is thought to be initiated by peripheral sensitization of the nociceptive system, which results from the increased activity of trigeminal nociceptors. Peripheral sensitization is characterized by an increased level of neuronal excitability and a lowering of the threshold for activation. Glial cells, earlier thought to serve only a supportive role, are now known to modulate the neuronal function and activity in the trigeminal ganglion directly [62].

Trigeminal ganglia comprise neurons and two types of glial cells, satellite cells and Schwann cells, which are associated with nerve fibers and produce the myelin sheet. The cell bodies of the primary afferent neurons that convey sen- 
sory information from the periphery to the CNS are completely surrounded by satellite cells, while the Schwann cells are associated with neuronal processes that project both to the periphery and to the CNS. Morphological studies have shown that processes of glial cells lie in close proximity to the plasma membrane of neurons. It is now accepted that glial cells, which outnumber the neurons in trigeminal ganglia, influence neuronal activity directly by controlling the microenvironment in the ganglion $[63,64]$.

Neuronal-glial cell communication via gap junctions is rapidly and markedly enhanced following the activation of nociceptive neurons by capsaicin [62]. Elevated gap junction activity is observed only between neurons and satellite glial cells, but not between Schwann cells. In vitro studies have provided evidence that CGRP release from neurons may activate adjacent satellite cells and promote the release of inflammatory cytokines. Increased levels of cytokines have been shown to result in local inflammatory reactions and modulation of the neuronal function $[65,66]$. In this way, CGRP could function as a paracrine factor to stimulate nearby neurons and glial cells within a cluster and also cause excitation of more distant neurons and glia located in other clusters, thereby propagating an inflammatory signal across the entire ganglion. Patients with migraine headache often feel sinus pain and pressure, which involve the activation of sensory C-fibers in the maxillary region of the trigeminal ganglion. Such commonly reported symptoms associated with migraine headache may be explained by the propagation of inflammatory signals within the trigeminal ganglion.

\section{Neuron-glia Signaling in the Trigeminal Subnucleus Caudalis}

It is becoming increasingly evident that the cellular changes associated with the central sensitization of nociceptive pathways are not restricted to neurons. Non-neuronal cell types, and particularly glial cells (mainly astrocytes and microglia) in the CNS are activated by inflammation or peripheral nerve injury and are involved in the transmission of nociceptive information and central sensitization. Astrocytes and microglia participate in neuronal sensitization by releasing cytokines or glutamate, modifying synaptic transmission [67-69].

Recent studies have demonstrated that trigeminal central sensitization also involves glial activation [70]. Morphological studies have revealed a close relationship between astrocytes and nerve endings in the subnucleus caudalis of the nucleus tractus spinalis nervi trigemini, suggesting that astrocytes may play a role in the transmission of nociceptive information. The morphological interrelationship between the astrocytes and the nerve endings in laminae I and II of the subnucleus caudalis has been identified by doublelabeling electron microscopic immunohistochemistry [71]. In a model of trigeminal central sensitization induced by the application of mustard oil to the rat tooth pulp, intrathecal administration of fluoroacetate (an inhibitor of the astroglial metabolic enzyme aconitase) markedly attenuated the increases in receptive field size, the responses to noxious stimuli and the decrease in the threshold of neurons in the trigeminal subnucleus caudalis [72]. Furthermore, mustard oilinduced central sensitization could be significantly attenuated by the continuous intrathecal superfusion of methionine sulfoximine, an inhibitor of astroglial glutamine synthetase [73].

The glial mechanisms in trigeminal central sensitization most likely involve their interactions with the glutamatergic receptors. It has been demonstrated that astrocytes may influence the presynaptic terminals directly through the activation of presynaptic glutamatergic mechanisms by increasing the probability of neurotransmitter release from nerve terminals and modulating synaptic transmission $[74,75]$. The involvement of NMDA receptors may, at least in part, be related with the phosphorylation mediated by interleukin-1 receptor signaling. Tumor necrosis factor $\alpha$ produced by microglial cells also enhances synaptic efficacy by increasing the surface expression of AMPA receptors on cultured neurons [76].

Some experimental findings suggest that the involvement of glial cells in trigeminal central sensitization may also be related with the activation of purinergic receptors. It has been reported that ATP stimulates the release of brainderived neurotrophic factor from microglia, which causes a depolarizing shift in the anion reversal potential in spinal lamina I neurons [77]. The glial activation may additionally mediate the sensitization by controlling the local microcirculation through purinergic receptors. It has been postulated that one of their physiological roles is to mediate vasodilatation in response to increased neural activity during sensitization [78].

\section{PATHOPHYSIOLOGICAL CONDITIONS AFFECT- ING THE ACTIVITY OF CAPSAICIN-SENSITIVE NERVES}

\section{Conditions Impairing TRPV1-Mediated Nociceptive Responses}

Neuropathic changes that affect trigeminal nociceptive neurons may alter their function, initiating meningeal neurogenic inflammation and the transmission of pain impulses toward the CNS. Metabolic and inflammatory diseases or toxic effects of different drugs affect the functional integrity of sensory nerve fibers. By far the greatest number of clinical and experimental data is available on diabetic neuropathic alterations and their effects on headache conditions.

\section{Diabetic Neuropathy}

In humans diabetic neuropathy affects both myelinated and unmyelinated nerve fibers, which results in disturbances in autonomic, motor and sensory functions, including the sensation of pain [79-81]. Clinical observations indicate that diabetic patients suffer more than non-diabetics from headaches. The onset of migraine or tension-type headaches frequently occurs concomitantly with the onset of diabetes mellitus. Increases in the frequency and duration of headache attacks have also been noted in patients with diabetes [82, 83].

Studies involving an established animal model of headaches have revealed that meningeal neurogenic sensory vasodilatation, elicited by activation of the TRPV1 receptors in intact rats, is absent in the dura mater of diabetic rats 6 weeks after the induction of diabetes with streptozotocin. In vitro measurement of the capsaicin-induced release of CGRP revealed an attenuated peptide release from preparations of 
the dura mater of diabetic rats. Treatment of diabetic rats with insulin restored both the vasodilatory response and the meningeal release of CGRP toward control levels. Diminished arterial smooth muscle sensitivity or an impairment of the endothelial function is unlikely to contribute to the reduction of neurogenic sensory vasodilatation at this stage of experimental diabetes mellitus, since changes were not observed in the vasodilatory effects of CGRP, histamine and acetylcholine acting directly on the vascular smooth muscle or endothelial cells [27]. In diabetes, an insufficient vasodilator function of the meningeal sensory nerves may result in disturbances of tissue homeostasis, e.g. through a reduced clearance of inflammatory mediators, ultimately inducing further activation and/or sensitization of meningeal nociceptors and cranial pain. A dysfunction of paravascular peptidergic afferent vasodilatory nerves may be implicated in the mechanisms which contribute to the increased incidence and severity of headaches in diabetic patients $[82,83]$.

\section{Sensitization of Meningeal Chemosensitive Afferent Nerves}

Phosphorylation of the TRPV1 receptors on sensory nerve fibers increases the probability of the ion channel opening in response to heat, protons and endogenous ligands and may result in sensitization of the channel. Prostaglandin $E_{2}$, bradykinin, nerve growth factor, ATP, glutamate, trypsin/tryptase and prolactin are pro-inflammatory mediators that activate their receptors through activation of the phospholipase $\mathrm{C}$, phospholipase $\mathrm{A}_{2}$, adenylyl cyclase, protein kinase $\mathrm{C}$ and protein kinase A signaling pathways, leading to sensitization of the TRPV1 receptor via phosphorylation. Sensitization of the TRPV1 channels localized on capsaicinsensitive trigeminal sensory nerves seems to be a key mechanism in the pathophysiology of headaches [84, 85].

\section{Protease-activated Receptor-2}

Morphological findings have demonstrated that TRPV1 receptors and a member of the protease-activated receptor (PAR) family, PAR-2, are co-localized in a significant population of nerve fibers associated with blood vessels or running freely in the stroma of the dura mater [86]. Trypsin or mast cell tryptase cleaves and activates this $G$ proteincoupled receptor, which plays important roles in the responses to injury, inflammation and tissue repair $[87,88]$. In the rat dura mater, activation of PAR-2 induces marked vasodilatation, which involves the release of CGRP from capsaicin-sensitive afferent nerves and the release of NO from endothelial cells. In an open cranial window preparation, pretreatment of the dura mater with the PAR-2 agonist peptide Ser-Leu-Ile-Gly-Arg-Leu-amide (SLIGRL-NH ${ }_{2}$ ) markedly enhanced the vasodilatory effect of capsaicin. These findings indicated that activation of PAR-2 may modulate the meningeal nociceptor function by initiating neuronal signaling mechanisms, leading to sensitization of the TRPV1 receptor expressed by capsaicin-sensitive afferent nerves [86]. Under pathophysiological conditions, the release of neuropeptides from sensory nerves may degranulate mast cells, giving rise to further sensitization of capsaicin-sensitive trigeminal nerves by PAR-2. The development of a vicious circle initiated by the release of CGRP and/or SP from capsaicin-sensitive trigeminal nerves may contribute significantly to the pathomechanisms of headaches.

\section{Ethanol}

Alcoholic drinks and other products containing alcohol may cause headaches in susceptible patients. The alcoholinduced headache generally occurs 30-45 minutes after the consumption of alcohol, which corresponds to the time needed for complete absorption from the gastrointestinal tract. Alcoholic beverages also trigger migraine and cluster headache attacks [89]. Although alcohol may impair cerebral autoregulation and depresses the cerebral serotonin turnover, which may contribute to the pathomechanism of alcoholinduced headaches [90], recent studies clarified a stimulating/sensitizing effect of ethanol on TRPV1 receptors of primary sensory neurons [91]. The intragastric administration of ethanol induced neurogenic inflammation in the dura mater of guinea pigs [92]. Both meningeal vasodilatation and the increased plasma extravasation of the dura mater were induced by the ingestion of ethanol, but these increases were reduced by pretreatment with the TRPV1 receptor antagonist capsazepine and antagonists for the CGRP and NK1 receptors. In an in vitro preparation, ethanol-induced release of neuropeptides from the dura mater was abolished by $\mathrm{Ca}^{2+}$ removal, capsaicin pretreatment and the TRPV1 antagonist, capsazepine. The protein kinase $\mathrm{C}$ pathway has been reported to contribute to the ethanol-induced sensitization of the TRPV1 receptor [91].

\section{Sensitization of Capsaicin-Sensitive Trigeminal Mecha- nisms by Nitric Oxide}

As a potent vasodilator and an agent involved in the sensitization of primary and secondary neurons of trigeminal pathways, NO has been suggested to contribute to the pathophysiology of primary headaches [93]. Clinical studies have demonstrated that an NO donor such as glyceryl trinitrate (GTN) may trigger a migraine attack. In a pilot study administration of an NOS inhibitor was effective in the treatment of migraine headache. Some human studies have also indicated abnormalities in metabolites of $\mathrm{NO}$ in headache patients [94].

Animal studies have provided important data on the pathophysiological role of NO in trigeminovascular activation. Different forms of NOS have been demonstrated in endothelial cells, mast cells and some nerve fibers of the dura mater [95]. Enzyme activity has also been detected in some trigeminal ganglion cells and the TNC [96, 97]. Subcutaneous injection of GTN has been found to produce a significant increase in NOS activity and c-fos protein-like immunoreactivity in the TNC [98] and brainstem nuclei [99] in rats. Following the infusion of GTN, the responses of neurons to electrical stimulation of periorbital cutaneous nerves were potentiated and the thresholds for the activation of TNC neurons by stimulation of the dural afferents were reduced. Activation is thought to be mediated by an effect of NO on unmyelinated nociceptive trigeminal fibers, since it was abolished after capsaicin pretreatment [100]. The role of capsaicin-sensitive trigeminal nociceptors in NO-induced sensitization is further corroborated by the observation that an intradermal injection of capsaicin into the periorbital area increased the expression of c-fos in the TNC which was significantly potentiated by GTN infusion [101]. Although the exact mechanism of NO-induced sensitization of capsaicinsensitive trigeminal neurons has not yet been elucidated, the 
experimental data indicate a potentiating effect of $\mathrm{NO}$ on the release of vasodilator neuropeptides such as CGRP from primary sensory neurons [102].

\section{ENDOGENOUS LIGANDS ACTING ON THE TRPV1 RECEPTOR: ENDOVANILLOIDS}

Endovanilloids are endogenous ligands of the nonselective cation channel TRPV1 receptor [103]. It has been suggested that, besides heat and low $\mathrm{pH}(<4.3)$, TRPV1 receptors are activated by certain arachidonic acid metabolites acting as endogenous ligands of the ion channel. To classify a molecule as an endovanilloid, the compound should be synthesized and released in sufficient amount to evoke a TRPV1-mediated response by direct activation of the channel. To control TRPV1 signaling, endovanilloids should be inactivated within a short time-span. As the binding site for an endogenous ligand acting on the TRPV1 receptor is intracellular, it might be expected that endogenous ligands are produced intracellularly or transported into the cell.

Arachidonylethanolamide (anandamide, AEA) is probably the most widely studied endogenous ligand in the trigeminal system that acts on both cannabinoid and TRPV1 receptors. AEA is believed to be primarily an endogenous ligand to the cannabinoid receptors $[104,105]$ found in the central and peripheral nervous systems. Cannabinoid CB1 receptors are localized on nerve fibers in the spinal trigeminal tract and the spinal TNC [106]. In a study involving the use of intravital microscopy, AEA acted via the CB1 receptor to inhibit the dural blood vessel dilatation brought about in the rat by electrical stimulation of the dura mater or the systemic administration of CGRP, capsaicin and NO [107]. AEA appears to act both presynaptically to prevent CGRP release from the trigeminal sensory nerves, and postsynaptically to inhibit CGRP-induced NO release in the wall of the dural arteries. Besides acting at the CB1 receptor, AEA has been found to act as an agonist on the TRPV1 receptor [108], and it is able to activate sensory neurons via the TRPV1 receptor. AEA activates the TRPV1 receptor in a similar way to capsaicin, promoting the release of CGRP and causing dural vasodilatation [102]. This CGRP-induced vasodilatation is in marked contrast to the inhibitory effects of AEA on neurogenic vasodilatation [107]. The dual effect of AEA on CGRP release mediated by different receptors on capsaicinsensitive nerve fibers may be an important regulatory mechanism affecting both pain transmission and blood flow changes in the meningeal tissues. The sensitivities of the TRPV1 and CB1 receptors for AEA on trigeminal neurons may differ, since the doses of AEA required to produce a maximal dilator response was much higher than that necessary to inhibit neurogenically induced vasodilatation [109]. The interpretation of these experimental results is difficult since the i.v. administration of AEA had a significant impact on the systemic blood pressure of the experimental animals. Experimental studies clarifying the effects of topically applied AEA on the dura mater may provide more reliable data concerning the participation of TRPV1 and CB1 receptors in the activation of capsaicin-sensitive meningeal nerve fibers. Much less information is available on the possible roles of other endovanilloids on the activity of meningeal nociceptors and on blood flow. N-arachidonyl-dopamine (NADA) and $\mathrm{N}$-oleoyl-dopamine (OLDA) have been identified as en- dogenous compounds acting on both TRPV1 and CB1 receptors, but OLDA proved to be much more selective for TRPV1 receptors. Clarification of the physiological role of endogenous vanilloids in meningeal tissues may provide further insights into the role of TRPV1 and CB1 receptors in the pathophysiology of the trigeminovascular system and headaches.

\section{ANIMAL MODELS OF HEADACHES UTILIZING CAPSAICIN}

In animal experiments, capsaicin either applied directly onto the surface of the exposed dura mater in a rat open cranial window preparation or injected intracisternally activates the trigeminovascular nociceptive afferents $[12,110]$. Stimulation of the trigeminal nociceptive nerve fibers with capsaicin activates face-grooming nociceptive behavior [111$113]$, and induces changes in the blood flow of the meningeal tissues and neurochemical changes in second-order neurons of the trigeminal brain stem nuclei. Animal models involving capsaicin application are generally accepted as models of meningeal nociception and headache.

The expression of c-fos protein induced experimentally within the TNC by chemical stimulation of the trigeminovascular system has been described. C-fos protein is a transcription factor expressed by the immediate-early response of the c-fos gene and is a widely used marker of increased neuronal activity. Nociceptive stimulation of the dura mater with capsaicin or intracisternal capsaicin infusion increases the number of c-fos-like immunoreactive neurons within the TNC [114]. In these animal models, c-fos expression in layers I and II of the TNC is used to monitor the activation of the TNC. C-fos expression induced by capsaicin application was attenuated by pharmacological agents used for the treatment of migraine. In a conscious rat model of trigeminal nociception and cerebral c-fos expression, the pattern of brain activity could be demonstrated after noxious trigeminal stimulation with intracisternal capsaicin administration. The level of c-fos immunoreactivity was significantly increased in the TNC (layers I and II), the area postrema, the nucleus of the solitary tract, the parvicellular reticular nucleus, the locus coeruleus, the parabrachial nucleus and the raphe nuclei. In addition, the ventrolateral periaqueductal gray, and the intralaminar thalamic and various hypothalamic areas also displayed enhanced c-fos expression. Other responding areas were the amygdala, the upper lip and forelimb regions of the primary somatosensory cortex, and the insula [115].

The rat open cranial window model provides an opportunity for the direct measurement of the blood flow changes induced by the activation of trigeminal nociceptive afferents. Application of capsaicin onto the exposed parietal dura mater induces a significant increase in meningeal blood flow as measured by laser Doppler flowmetry [12]. This effect is mediated by the activation of TRPV1 receptors, as evidenced by the inhibition of the response by capsazepine, a TRPV1 receptor antagonist, and by prior systemic or local desensitization with capsaicin. Vasodilatation induced by the release of neuropeptides from activated trigeminal nerve endings may be a significant component of the pathophysiology of headaches probably involved in the fast elimination of proinflammatory agents from the meninges. 
Animal models in which capsaicin is used as a nociceptive stimulus provide a reliable experimental approach for study of the pathophysiological mechanisms activated in human headaches and to test the effects of pharmachological agents on meningeal nociceptive reactions [116,117].

\section{THE TRPV1-CGRP SYNAPSE}

\section{The TRPV1 Receptor as a Target for Headache Ther- apy}

The TRPV1 receptor is a molecular integrator of different physical and chemical noxious stimuli affecting sensory nerve endings. Pharmacological control of the TRPV1 receptor function represents a new strategy for pain relief in headaches. Agonists of the TRPV1 receptor have a desensitizing and probably also a neurotoxic effect on chemosensitive primary sensory neurons $[12,15,17,18,36,118,119]$. TRPV1 receptor antagonists may interrupt the trigeminal transmission of sensory information and prevent the sensitization of nociceptive fibers that may occur in migraine.

The blockade of CGRP receptors has recently been demonstrated to serve as effective treatment for migraine attacks. Since a significant fraction of trigeminal ganglion neurons synthesizing the vasodilator neuropeptide CGRP are chemosensitive neurons expressing the TRPV1 receptor, CGRP receptor antagonists may act, at least partly, as inhibitors of the vasodilatation in dural blood vessels and the transmission of nociceptive impulses to the CNS induced by the activation of chemosensitive nerve fibers [120,121].

\section{TRPV1 Antagonists}

Prolonged excitation of trigeminal primary afferents causing the sensitization of second-order neurons in the spinal trigeminal nucleus can be inhibited by mechanisms which reduce the depolarization of sensory afferents and the release of neuropeptide and amino acid transmitters from their central terminals. Antagonists of the TRPV1 receptor have been sought because of their potential to interrupt the transmission of noxious signals from the periphery by preventing neuropeptide release, the development of sensitization and reversal of the effects of sensitization of secondorder neurons [122]. It has been observed that the expression of TRPV1 is increased in chronic pain states [123, 124], and it has been proposed that such increased expression plays a role in the development of trigeminal sensitization in headache patients.

TRPV1 antagonists are particularly potent and efficacious in preclinical pain models associated with low $\mathrm{pH}$ and thermal hyperalgesia, such as acute and chronic inflammation. The encouraging activity of SB-705498 (N-(2bromophenyl)-N'-[((R)-1-(5-trifluoromethyl-2-pyridyl) pyrrolidin-3-yl)] urea) in preclinical pain models prompted its subsequent clinical evaluation [125]. In experimental studies the i.v. administration of the TRPV1 receptor antagonist SB705498 induced a small, but significant suppression of second-order neuronal responses to stimulation of both dura mater and facial skin afferents in rats. SB-705498 reversed and prevented the sensitization induced by the dural application of ,inflammatory soup" containing histamine, serotonin, bradykinin and prostaglandin $\mathrm{E}_{2}$ at $\mathrm{pH} 5.0$ [122].
These experimental results may be relevant both to the mechanisms of trigeminovascular sensitization and to the development of allodynia in some forms of migraine. It might also point the way to a therapeutic approach to prevent or reverse these symptoms when they occur. Clinical trials of SB-705498 to evaluate the efficacy in patients experiencing migraine have been completed, but the results have not yet been published. However, the use of TRPV1 antagonists may be limited by their effects in producing hyperthermia. The mechanisms of TRPV1 antagonist-induced hyperthermia include peripheral vasoconstriction that reduces heat loss and an increase in metabolic heat production measured by increased oxygen consumption in rats. However, it is unclear whether presumed capsaicin-sensitive hypothalamic thermosensitive neurons $[126,127]$ contribute to these thermoregulatory effects [128-130].

\section{TRPV1 Agonists}

Clinical studies of intranasal capsaicin administration have demonstrated its effectiveness in relieving cluster headaches. [131-133]. However, the initial application of the strongly irritant capsaicin is accompanied by an acute burning sensation, which is lost on repeated applications as the neurons become desensitized. This irritant property of capsaicin has limited its clinical use. Civamide (cis-8-methyl- $N$ vanillyl-6-nonenamide), a synthetic isomer of capsaicin which is less irritating than capsaicin itself, acts as a TRPV1 receptor agonist [134] that depletes the neurotransmitter content of capsaicin-sensitive nerve fibers and is significantly more potent than capsaicin at depleting CGRP and SP from sensory neurons. Civamide has been evaluated clinically as intranasal treatment for the relief of migraine headache [135]. Intranasal application of civamide solution reduced the number of cluster headache episodes, pain intensity and associated symptoms during and after the treatment, suggesting the potential utility of TRPV1 receptor agonists for the prevention of cluster headache [136].

\section{Substances Inhibiting Transmitter Release from Tri- geminal Nerve Endings}

A variety of different prejunctional receptors located on the trigeminal sensory neurons may also regulate transmitter release upon activation. Transmitter release can be modified on both the peripheral and central terminals of primary sensory neurons, inhibiting the local neurogenic inflammation and the excitation of the second-order neurons, respectively.

5-hydroxytryptamine $\left(5-\mathrm{HT}_{1 \mathrm{D}, 1 \mathrm{~F}}\right), \alpha_{2}$-adrenoceptor, $\mathrm{H}_{3}$ histamine, $\mu$-opioid and somatostatin receptors have been identified on trigeminovascular afferent nerves [55, 137, 138]. The inhibition of transmitter release mediated by these receptors may explain some success of somatostatin, adrenaline or narcotics in the relief of headaches. Among the drugs acting on presynaptic receptors, only the $5-\mathrm{HT}_{1 \mathrm{D}, 1 \mathrm{~F}}$ receptor agonist triptans are widely and succesfully used in the therapy of primary headaches. Triptans act on both the neuronal and the vascular 5-HT receptors, reducing neuropeptide release and blood flow in the pain-sensitive dura mater [139, 140]. Sumatriptan as well as the newer triptans display high affinity at $5-\mathrm{HT}_{1}$ receptor subtypes. They have high affinity for both $5-\mathrm{HT}_{1 \mathrm{~B}}$ and $5-\mathrm{HT}_{1 \mathrm{D}}$ receptors, with sumatriptan being the weakest at the $5-\mathrm{HT}_{1 \mathrm{~B}}$ and almotriptan the weakest at 
the $5-\mathrm{HT}_{1 \mathrm{D}}$ receptor. The development of receptor subtypespecific compounds and antibodies has allowed the precise identification of its vascular and neuronal sites of action, thereby providing a basis for the understanding of the pathophysiology and a more precisely targeted therapeutic approach. 5-HT receptor subtypes are distributed differentially within the human trigeminovascular system. Vasoconstrictor responses to triptans are mediated by the vascular $5 \mathrm{HT}_{1 \mathrm{~B}}$ receptor [141-143]. 5- $\mathrm{HT}_{1 \mathrm{D}}$ and $5-\mathrm{HT}_{1 \mathrm{~F}}$ receptors are localized in trigeminal sensory neurons, including the peripheral projections to the dura mater and the trigeminal nuclear complex and the solitary tract of the brainstem. These brainstem regions are known to possess binding sites for sumatriptan and zolmitriptan, as detected by autoradiographic studies in rats and guinea pigs [144]. Selective 5-HT $1 \mathrm{D}, 1 \mathrm{~F}$ receptor agonists may therefore decrease headaches by reducing neuropeptide release, inhibiting neurogenic inflammation in the dura mater and blocking neurotransmission, without the potential side-effects mediated through $5-\mathrm{HT}_{1 \mathrm{~B}}$ receptor activation (i.e. vasoconstriction also in coronary and carotid arteries). Experimental results indicate that the vast majority of $5-\mathrm{HT}_{1 \mathrm{D}}$-immunoreactive trigeminal neurons posses unmyelinated peptidergic axons that innervate the dura mater. In the TNC 5- $\mathrm{HT}_{1 \mathrm{D}}$-immunoreactive fibers are concentrated in Rexed laminae I and II, whereas a few axons penetrate into lamina V. 5- $\mathrm{HT}_{1 \mathrm{D}}$ receptor immunoreactivity is found primarily within small-diameter, unmyelinated, peptidergic nociceptors of the trigeminal ganglia. When $5-\mathrm{HT}_{1 \mathrm{D}^{-}}$ immunoreactive terminals in the superficial laminae of the TNC were examined at the electron microscopic level, it was found that the receptor concentrated in dense-core vesicles, which also contained SP [145]. The highly effective antimigraine potency of selective 5- $\mathrm{HT}_{1 \mathrm{D}}$ and the putative $5-\mathrm{HT}_{1 \mathrm{~F}}$ receptor agonists may be mediated, at least in part, by modulation of the activity of capsaicin-sensitive meningeal afferent nerves and also by inhibition of the release of SP and other vasoactive neuropeptides from capsaicin-sensitive nociceptors.

\section{Non-peptide CGRP Receptor Antagonists}

CGRP plays a central role in the pathophysiology of headaches through its involvement in both the central and peripheral mechanisms of meningeal nociception. BIBN4096 (olcegepant), which inhibits CGRP-induced vasodilatation, is the first non-peptide CGRP antagonist for migraine therapy that has been tested in clinical trials [120]. Olcegepant is well tolerated and effective in migraine attacks [121]. Its main limitation is its poor oral bioavailability, so that it has only been tested through i.v. administration.

MK-0974 (telcagepant) is another non-peptide oral CGRP receptor antagonist that has been developed for the treatment of migraine [146]. This compound blocks CGRP receptors and may inhibit the dilatation of dural vessels and reduce neurotransmission in the CNS, resulting in pain relief. Telcagepant itself does not cause vasoconstriction. Data from clinical trials suggest that the value of telcagepant for the acute treatment of migraine is comparable with that of triptan compounds, including pain relief and freedom from pain for 2 hours. However, recent data revealed a potential hepatotoxicity risk when telcagepant was dosed daily, which may limit its applicability in migraine prevention $[147,148]$.

\section{CONCLUDING REMARKS}

Primary sensory neurons expressing the TRPV1/ capsaicin receptor, a molecular integrator of a variety of nociceptive stimuli, play a fundamental role in pain sensation. Morphological and functional studies in the rat dura mater have disclosed a widespread system of capsaicin-sensitive TRPV1-immunoreactive nerve fibers and their contribution to meningeal vascular reactions. The meningeal neurogenic sensory vasodilator responses elicited by activation of the TRPV1 receptor are mediated by the release of CGRP from sensory nerves, which suggests that similar mechanisms may operate in humans during migraine attacks, when an increased concentration of CGRP is measured in the jugular venous blood. Capsaicin-sensitive trigeminal afferent nerves also contribute to the vasodilatory responses induced by the activation of PAR-2, which may also sensitize meningeal afferent nerves. Demonstration of the colocalization of PAR2 and TRPV1 receptors in the meningeal axons lends further support to this mechanism. The neurogenic vasodilatation mediated by capsaicin-sensitive afferent nerves may serve a protective function through the elimination of inflammatory mediators from the meningeal tissue, a mechanism which may play a role in the resolution of headaches. Pathological conditions such as diabetes mellitus may compromise this protective mechanism. Indeed, the function of trigeminovascular nociceptive neurons is impaired by diabetes mellitus through decreases in the expression of the TRPV1 receptor and the release of CGRP from the affected neurons.

These observations indicate an important role of capsaicin-sensitive meningeal afferent nerves in the pathophysiology of headaches and suggest that pharmacological manipulation of the TRPV1 receptor may offer a promising approach to the management of headaches.

\section{ACKNOWLEDGMENT}

This work was supported in part by research grants OTKA K63663, ETT 193/2006 and RET-08/2004.

\section{REFERENCES}

[1] Hargreaves, R.J.; Shepheard, S.L. Pathophysiology of migrainenew insights. Can. J. Neurol. Sci., 1999, 6, (Suppl 3), S12-19.

[2] Buzzi, M.G.; Moskowitz, M.A. The pathophysiology of migraine. J. Headache Pain, 2005, 6, 105-111.

[3] Messlinger, K. Migraine: where and how does the pain originate? Exp. Brain Res., 2009, 196, 179-193.

[4] Mione, M.C.; Cavanagh, J.F.R.; Kirkpatrick, K.A.; Burnstock, G. Plasticity in expression of calcitonin gene-related peptide and substance $\mathrm{P}$ immunoreactivity in ganglia and fibres following guanethidine and/or capsaicin denervation. Cell. Tissue Res., 1992, 268, 491-504.

[5] Messlinger, K.; Hanesch, U.; Baumgärtel, M.; Trost, B.; Schmidt, R.F. Innervation of the dura mater encephali of cat and rat: ultrastructure and calcitonin gene-related peptide-like and substance Plike immunoreactivity. Anat. Embryol., 1993, 188, 219-237.

[6] Edvinsson, L.; Gulbenkian, S.; Barroso, C.P.; Cunha e Sá, M.; Polak, J.M.; Mortensen, A.; Jorgensen, L.; Jansen-Olesen, I. Innervation of the human middle meningeal artery: immunohistochemistry, untrastructure, and role of endothelium for vasomotility. Peptides, 1998, 19, 1213-1225.

[7] Edvinsson, L.; Uddman, R. Adrenergic, cholinergic and peptidergic nerve fibres in dura mater - involvement in headache? Cephalalgia, 1981, 1, 175-179.

[8] Dimitriadou, V.; Buzzi, M.G.; Theoharides, T.C.; Moskowitz, M.A. Ultrastructural evidence for neurogenically mediated changes 
in blood vessels of the rat dura mater and tongue following antidromic trigeminal stimulation. Neuroscience, 1992, 48, 187-203.

[9] Moskowitz, M.A. The neurobiology of vascular head pain. Ann. Neurol., 1984, 16, 157-168.

[10] Goadsby, P.J.; Edvinsson, L.; Ekman, R. Vasoactive peptide release in the extracerebral circulation of humans during migraine headache. Ann. Neurol., 1990, 28, 183-187.

[11] Goadsby, P.J.; Edvinsson, L. Human in vivo evidence for trigeminovascular activation in cluster headache. Neuropeptide changes and effects of acute attacks therapies. Brain, 1994, 117, 427-434.

[12] Dux, M.; Sántha, P.; Jancsó, G. Capsaicin-sensitive neurogenic sensory vasodilatation in the dura mater of the rat. J. Physiol., 2003, 552, 859-867.

[13] Jancsó, N.; Jancsó-Gábor, A.; Szolcsányi, J. The role of the sensory nerve endings in neurogenic inflammation induced in human skin and in the eye and paw of the rat. Br. J. Pharmacol. Chemoter., 1968, 33, 32-41.

[14] Jancsó, G.; Király, E.; Jancsó-Gábor, A. Chemosensitive pain fibres and inflammation. Int. J. Tissue React., 1980, 2, 57-66.

[15] Jancsó, G.; Király, E.; Such, G.; Joó, F.; Nagy, A. Neurotoxic effect of capsaicin in mammals. Acta Physiol. Hung., 1987, 69, 295-314.

[16] Buck, S.H.; Burks, T.F. The neuropharmacology of capsaicin:review of some recent observations. Pharmacol. Rev., 1986, $38,179-226$

[17] Holzer, P. Capsaicin: cellular targets, mechanisms of action, and selectivity for thin sensory neurons. Pharmacol. Rev., 1991, 43(2), 143-201.

[18] Szallasi, A.; Blumberg, P.M. Vanilloid (Capsaicin) receptors and mechanisms. Pharmacol. Rev., 1999, 51, 159-212.

[19] Andres, K.H.; von Düring, M.; Muszynski, K.; Schmidt, R.F. Nerve fibres and their terminals of the dura mater encephali of the rat. Anat. Embryol. (Berl), 1987, 175(3), 289-301.

[20] Amenta, F.; Sancesario, G.; Ferrante, F.; Cavallotti, C. Acetylcholinesterase-containing nerve fibers in the dura mater of guinea pig, mouse, and rat. J. Neural Transm., 1980, 47(3), 237-242.

[21] Jancsó, N. Desensitization with capsaicin as a tool for studying the function of pain receptors. In: Pharmacology of Pain; Lim, R.K.S. Ed.; Pergamon Press: Oxford, 1968; pp. 33-55.

[22] Jancsó, G., Király, E.; Jancsó-Gábor, A. Pharmacologically induced selective degeneration of chemosensitive primary sensory neurones. Nature, 1977, 270, 741-743.

[23] Jancsó, G. Pathobiological reactions of C-fibre primary sensory neurones to peripheral nerve injury. Exp. Physiol., 1992, 77, 405431.

[24] Caterina, M.J.; Schumacher, M.A.; Tominaga, M.; Rosen, T.A.; Levine, J.D.; Julius, D. The capsaicin receptor: a heat-activated ion channel in the pain pathway. Nature, 1997, 389, 816-824.

[25] Tominaga, M.; Caterina, M.J.; Malmberg, A.B.; Rosen, T.A.; Gilbert, H.; Skinner, K.; Raumann, BE.; Basbaum, A.I.; Julius, D. The cloned capsaicin receptor integrates multiple pain-producing stimuli. Neuron, 1998, 21, 531-543.

[26] Dux, M.; Messlinger, K. Neurogenic vascular responses in the dura mater and their relevance for the pathophysiology of headaches. In: Neurogenic Inflammation in Health and Disease. Neuroimmune Biology; Jancsó, G. Ed.; Elsevier, 2008; Vol. 8, pp. 193-209.

[27] Dux, M.; Rosta, J.; Pintér, S.; Sántha, P.; Jancsó, G. Loss of capsaicin-induced meningeal neurogenic sensory vasodilatation in diabetic rats. Neuroscience, 2007, 150, 194-201.

[28] Akerman, S.; Kaube, H.; Goadsby, P.J. Vanilloid type 1 receptors (VR1) on trigeminal sensory nerve fibres play a minor role in neurogenic dural vasodilatation, and are involved in capsaicin-induced dural dilation. Br. J. Pharmacol., 2003, 140(4),718-724.

[29] Strassman, A.M.; Levy, D. Response properties of dural nociceptors in relation to headache. J. Neurophysiol., 2006, 95(3), 12981306.

[30] Shimizu, T.; Toriumi, H.; Sato, H.; Shibata, M.; Nagata, E.; Gotoh, K.; Suzuki, N. Distribution and origin of TRPV1 receptorcontaining nerve fibers in the dura mater of rat. Brain Res., 2007, 1173, 84-91.

[31] Olesen, J.; Burstein, R.; Ashina, M.; Tfelt-Hansen, P. Origin of pain in migraine: evidence for peripheral sensitisation. Lancet $\mathrm{Neu}$ rol., 2009, 8, 679-690.

[32] Goadsby, P.J. Migraine, allodynia, sensitisation and all of that... Eur. Neurol., 2005, 53 (Suppl 1), 10-16.
[33] Toda, N.; Usui, H.; Nishino, N.; Fujiwara, M. Cardiovascular effects of capsaicin in dogs and rabbits. J. Pharmacol. Exp. Ther., 1972, 181, 512-521.

[34] Pórszász, R.; Porkoláb, Á.; Ferencz, A.; Pataki, T.; Szilvássy, Z.; Szolcsányi, J. Capsaicin-induced nonneural vasoconstriction in canine mesenteric arteries. Eur. J. Pharmacol., 2002, 441, 173-175.

[35] Gamse, R.; Lackner, D.; Gamse, G.; Leeman, S.E. Effect of capsaicin pretreatment on capsaicin-evoked release of immunoreactive somatostatin and substance $\mathrm{P}$ from primary sensory neurons. $\mathrm{N}-\mathrm{S}$ Arch. Pharmacol., 1981, 316(1), 38-41.

[36] Király, E.; Jancsó, G.; Hajós, M. Possible morphological correlates of capsaicin desensitization. Brain Res., 1991, 540, 279-282.

[37] Ferdinandy, P.; Csont, T.; Csonka, Cs.; Török, M.; Dux, M.; Németh, J.; Horváth, I.L.; Dux, L.; Szilvássy, Z.; Jancsó, G. Capsaicin-sensitive local sensory innervation is involved in pacinginduced preconditioning in rat hearts: role of nitric oxide and CGRP? N-S Arch. Pharmacol., 1997, 356, 356-363.

[38] Goadsby, P.J.; Edvinsson, L., Ekman, R. Release of vasoactive peptides in the extracerebral circulation of humans and the cat during activation of the trigeminovascular system. Ann. Neurol., 1988, 23, 193-196.

[39] Connor, K.M., Shapiro, R.E.; Diener, H.C., Lucas, S.; Kost, J.; Fan, X.; Fei, K., Assaid, C.; Lines, C.; Ho, T.W. Randomized, controlled trial of telcagepant for the acute treatment of migraine. $\mathrm{Neu}$ rology, 2009, 73, 970-977.

[40] Strassman, A.M.; Raymond, S.A. On the origin of headaches. Endeavour, 1997, 21, 97-100.

[41] Buzzi, M.G.; Sakas. D.E.; Moskowitz, M.A. Indomethacin and acetylsalicylic acid block neurogenic plasma protein extravasation in rat dura mater. Eur. J. Pharmacol., 1989, 165, 251-258.

[42] Sarchielli, P.; Alberti, A.; Baldi, A.; Coppola, F.; Rossi, C.; Pierguidi, L.; Floridi, A.; Calabresi, P. Proinflammatory cytokines, adhesion molecules, and lymphocyte integrin expression in the internal jugular blood of migraine patients without aura assessed ictally. Headache, 2006, 46, 200-207.

[43] Friberg, L. Cerebral blood flow changes in migraine: methods, observations and hypotheses. J. Neurol., 1991, 238 Suppl 1, 12-17.

[44] Markowitz, S.; Saito, K.; Moskowitz, M.A. Neurogenically mediated leakage of plasma protein occurs from blood vessels in dura mater but not brain. J. Neurosci., 1987, 7, 4129-4136.

[45] Fusayasu, E., Kowa, H.; Takeshima, T.; Nakaso, K.; Nakashima, K. Increased plasma substance P and CGRP levels, and high ACE activity in migraineurs during headache-free periods. Pain, 2007, 128(3), 209-214.

[46] Diener, H.C. RPR100893 Study Group. RPR100893, a substance-P antagonist, is not effective in the treatment of migraine attacks. Cephalalgia, 2003, 23(3), 183-185.

[47] Foreman J.C. Substance P and calcitonin gene-related peptide: effects on mast cells and in human skin. Int. Arch. Allergy Appl. Immunol., 1987, 82(3-4), 366-371.

[48] Dimitriadou, V., Buzzi, M.G.; Moskowitz, M.A.; Theoharides, T.C. Trigeminal sensory fiber stimulation induces morphological changes reflecting secretion in rat dura mater mast cells. Neuroscience, 1991, 44, 97-112.

[49] Huttunen, M.; Harvima, I.T.; Ackermann, L.; Harvima, R.J.; Naukkarinen, A.; Horsmanheimo, M. Neuropeptide- and capsaicininduced histamine release in skin monitored with the microdialysis technique. Acta Derm. Venereol., 1996, 76(3), 205-209.

[50] Ottosson, A., Edvinsson, L. Release of histamine from dural mast cells by substance $\mathrm{P}$ and calcitonin gene-related peptide. Cephalalgia, 1997, 17(3), 166-174.

[51] Dux, M.; Schwenger, N.; Messlinger, K. Possible role of histamine (H1- and H2-) receptors in the regulation of meningeal blood flow. Br. J. Pharmacol., 2002, 137(6), 874-880.

[52] Schwenger, N.; Dux, M.; de Col, R.; Carr, R.; Messlinger, K. Interaction of calcitonin gene-related peptide, nitric oxide and histamine release in neurogenic blood flow and afferent activation in the rat cranial dura mater. Cephalalgia, 2007, 27(6), 481-491.

[53] Martling, C.R. Sensory nerves containing tachykinins and CGRP in the lower airways. Functional implications for bronchoconstriction, vasodilatation and protein extravasation. Acta Physiol. Scand., Suppl. 1987, 563, 1-57.

[54] Harvima, I.T., Nilsson, G.; Naukkarinen, A. Role of mast cells and sensory nerves in skin inflammation. G. Ital. Dermatol. Venereol., 2010, 145(2), 195-204. 
[55] Matsubara, T.; Moskowitz, M.A.; Huang, Z. UK-14,304, R(-)alpha-methyl-histamine and SMS 201-995 block plasma protein leakage within dura mater by prejunctional mechanisms. Eur. J. Pharmacol., 1992, 224, 145-150.

[56] Ohkubo, T.; Shibata, M.; Inoue, M.; Kaya, H.; Takahashi, H. Regulation of substance $\mathrm{P}$ release mediated via prejunctional histamine H3 receptors. Eur. J. Pharmacol., 1995, 273, 83-88.

[57] Krabbe, A.A.; Olesen, J. Headache provocation by continuous intravenous infusion of histamine. Clinical results and receptor mechanisms. Pain, 1980, 8(2), 253-259

[58] Russell, D. Cluster headache: trial of a combined histamine H1 and H2 antagonist treatment. J. Neurol. Neurosurg. Psychiatry, 1979, 42(7), 668-669.

[59] Pulier, M.L. Antihistamine for cluster headache. Psychosomatics, 1988, 29(2), 244-245.

[60] Bolay, H.; Reuter, U.; Dunn, A.K.; Huang, Z.; Boas, D.A.; Moskowitz, M.A. Intrinsic brain activity triggers trigeminal meningeal afferents in a migraine model. Nat. Med., 2002, 8(2), 136-142.

[61] Moskowitz, M.A. Genes, proteases, cortical spreading depression and migraine: impact on pathophysiology and treatment. Funct. Neurol., 2007, 22(3), 133-136.

[62] Thalakoti, S.; Patil, V.V.; Damodaram, S.; Vause, C.V.; Langford, L.E.; Freeman, S.E.; Durham, P.L. Neuron-glia signaling in trigeminal ganglion: implications for migraine pathology. Headache, 2007, 47(7), 1008-1023, discussion 24-25.

[63] Pannese, E.; Ledda, M.; Cherkas, P.; Huang, T.; Hanani, M. Satellite cell reactions to axon injury of sensory ganglion neurons: Increase in number of gap junctions and formation of bridges connecting previously separate perineuronal sheaths. Anat. Embryol., 2003, 206, 337-347.

[64] Hanani, M. Satellite glial cells in sensory ganglia: From form to function. Brain Res. Brain Res. Rev., 2005, 48, 457-476.

[65] Rothwell, N.; Hopkins, S. Cytokines and the nervous system II: Actions and mechanisms of action. Trends Neurosci., 1995, 18, $130-136$

[66] Vitkovic, L.; Bockaert, J.; Jacque, C. "Inflammatory" cytokines: Neuromodulators in normal brain? J. Neurochem., 2000, 74, 457471 .

[67] Watkins, L.R.; Maier, S.F. Glia: a novel drug discovery target for clinical pain. Nat. Rev. Drug Discov., 2003, 2(12), 973-985.

[68] Watkins, L.R.; Maier, S.F. Glia and pain: past, present, and future. In: The Paths of Pain 1975-2005; Merskey, H.; Loeser, J.D.; Dubner, R. Eds.; IASP Press: Seattle, 2005; pp. 165-175.

[69] Tsuda, M.; Inoue, K.; Salter, M.W. Neuropathic pain and spinal microglia: a big problem from molecules in "small" glia. Trends Neurosci., 2005, 28, 101-107.

[70] Xie, Y.F.; Zhang, S.; Chiang, C.Y.; Hu, J.W.; Dostrovsky, J.O., Sessle, B.J. Involvement of glia in central sensitization in trigeminal subnucleus caudalis (medullary dorsal horn). Brain Behav. Immun., 2007, 21(5), 634-641.

[71] Yihong, Z.; Tamada, Y.; Akai, K.; Suwa, F. Morphological interrelationship between astrocytes and nerve endings in the rat spinal trigeminal nucleus caudalis. Okajimas Folia Anat, Jpn., 2006, 83(3), 91-96.

[72] Okada-Ogawa, A.; Suzuki, I.; Sessle, B.J.; Chiang, C.Y.; Salter, M.W.; Dostrovsky, J.O.; Tsuboi, Y.; Kondo, M.; Kitagawa, J.; Kobayashi, A.; Noma, N.; Imamura, Y.; Iwata, K. Astroglia in medullary dorsal horn (trigeminal spinal subnucleus caudalis) are involved in trigeminal neuropathic pain mechanisms. J. Neurosci., 2009, 29(36), 11161-11171.

[73] Chiang, C.Y.; Wang, J.; Xie, Y.F.; Zhang, S.; Hu, J.W.; Dostrovsky, J.O.; Sessle, B.J. Astroglial glutamate-glutamine shuttle is involved in central sensitization of nociceptive neurons in rat medullary dorsal horn. J. Neurosci., 2007, 27(34), 9068-9076.

[74] Hertz, L.; Zielke, H.R. Astrocytic control of glutamatergic activity: astrocytes as stars of the show. Trends Neurosci., 2004, 27, 735743.

[75] Fonseca, L.L.; Monteiro, M.A.; Alves, P.M., Carrondo, M.J., Santos, H. Cultures of rat astrocytes challenged with a steady supply of glutamate: new model to study flux distribution in the glutamateglutamine cycle. Glia, 2005, 51, 286-296.

[76] Beattie, E.C.; Stellwagen, D.; Morishita, W.; Bresnahan, J.C.; Ha, B.K.; Von Zastrow, M.; Beattie, M.S.; Malenka, R.C. Control of synaptic strength by glial TNFalpha. Science, 2002, 295(5563), 2282-2285.
[77] Coull, J.A.; Beggs, S.; Boudreau, D.; Boivin, D.; Tsuda, M.; Inoue, K.; Gravel, C., Salter, M.W.; De Koninck, Y. BDNF from microglia causes the shift in neuronal anion gradient underlying neuropathic pain. Nature, 2005, 438(7070), 1017-1021.

[78] Dietrich, H.H.; Horiuchi, T.; Xiang, C.; Hongo, K.; Falck, J.R.; Dacey, R.G.Jr. Mechanism of ATP-induced local and conducted vasomotor responses in isolated rat cerebral penetrating arterioles. J. Vasc. Res., 2009, 46(3), 253-264.

[79] Diemel, L.T.; Brewster, W.J.; Fernyhough, P.; Tomlinson, D.R Expression of neuropeptides in experimental diabetes; effects of treatment with nerve growth factor or brain-derived neurotrophic factor. Brain Res. Mol. Brain Res., 1994, 21(1-2), 171-175.

[80] Zochodne, D.W. Diabetic neuropathies: features and mechanisms. Brain Pathol., 1999, 9(2), 369-391.

[81] Song, J.X.; Wang, L.H.; Yao, L.; Xu, C.; Wei, Z.H.; Zheng, L.R. Impaired transient receptor potential vanilloid 1 in streptozotocininduced diabetic hearts. Int. J. Cardiol., 2009, 134(2), 290-292.

[82] Split, W.; Szydlowska, M. Headaches in non insulin-dependent diabetes mellitus. Funct. Neurol., 1997, 12, 327-332.

[83] Split, W.; Szdlowska, M. Tension-type headache in diabetes mellitus. Headache Q., 1998, 9, 145-148.

[84] Lee, S.Y.; Lee, J.H.; Kang, K.K.; Hwang, S.Y.; Choi, K.D.; Oh, U. Sensitization of vanilloid receptor involves an increase in the phosphorylated form of the channel. Arch. Pharm. Res., 2005, 28(4), 405-412.

[85] Wang, Y. The functional regulation of TRPV1 and its role in pain sensitization. Neurochem. Res., 2008, 33(10), 2008-2012.

[86] Dux, M.; Rosta, J.; Sántha, P.; Jancsó, G. Involvement of capsaicin-sensitive afferent nerves in the proteinase-activated receptor 2 -mediated vasodilatation in the rat dura mater. Neuroscience, 2009, 161(3), 887-894.

[87] Coelho, A.M.; Ossovskaya, V.; Bunnett, N.W. Proteinase-activated receptor-2: physiological and pathophysiological roles. Curr. Med. Chem. Cardiovasc. Hematol. Agents., 2003, 1(1), 61-72.

[88] Bunnett, N.W. Protease-activated receptors: how proteases signal to cells to cause inflammation and pain. Semin. Thromb. Hemost., 2006, 32 Suppl 1, 39-48.

[89] Panconesi, A. Alcohol and migraine: trigger factor, consumption, mechanisms. A review. J. Headache Pain, 2008, 9(1), 19-27.

[90] Altura, B.M.; Altura, B.T.; Gebrewold, A. Alcohol-induced spasms of cerebral blood vessels: relation to cerebrovascular accidents and sudden death. Science, 1983, 220(4594), 331-333.

[91] Trevisani, M.; Smart, D.; Gunthorpe, M.J.; Tognetto, M.; Barbieri, M.; Campi, B.; Amadesi, S.; Gray, J.; Jerman, J.C.; Brough, S.J.; Owen, D.; Smith, G.D.; Randall, A.D.; Harrison, S.; Bianchi, A.; Davis, J.B.; Geppetti, P. Ethanol elicits and potentiates nociceptor responses via the vanilloid receptor-1. Nat. Neurosci., 2002, 5(6), 546-551.

[92] Nicoletti, P.; Trevisani, M.; Manconi, M.; Gatti, R.; De Siena, G.; Zagli, G.; Benemei, S.; Capone, J.A.; Geppetti, P.; Pini, L.A. Ethanol causes neurogenic vasodilation by TRPV1 activation and CGRP release in the trigeminovascular system of the guinea pig. Cephalalgia, 2008, 28(1), 9-17.

[93] Thomsen, L.L.; Olesen, J. Nitric oxide in primary headaches. Curr Opin. Neurol., 2001, 14(3), 315-321.

[94] Olesen, J.; Jansen-Olesen, I. Nitric oxide mechanisms in migraine. Pathol. Biol. (Paris)., 2000, 48(7), 648-657.

[95] Berger, R.J.; Zuccarello, M.; Keller, J.T. Nitric oxide synthase immunoreactivity in the rat dura mater. Neuroreport, 1994, 5(4), 519-521

[96] Lazarov, N.E. Comparative analysis of the chemical neuroanatomy of the mammalian trigeminal ganglion and mesencephalic trigeminal nucleus. Prog. Neurobiol., 2002, 66(1), 19-59.

[97] Stoyanova, I.I.; Lazarov, N.E. Localization of nitric oxide synthase in rat trigeminal primary afferent neurons using NADPHdiaphorase histochemistry. Mol. Histol., 2005, 36(3), 187-193.

[98] Pardutz, A., Krizbai, I.; Multon, S.; Vecsei, L.; Schoenen, J. Systemic nitroglycerin increases nNOS levels in rat trigeminal nucleus caudalis. Neuroreport, 2000, 11(14), 3071-3075.

[99] Tassorelli, C.; Joseph, S.A. NADPH-diaphorase activity and Fos expression in brain nuclei following nitroglycerin administration. Brain Res., 1995, 695(1), 37-44.

[100] Tassorelli, C.; Joseph, S.A.; Nappi, G. Neurochemical mechanisms of nitroglycerin-induced neuronal activation in rat brain: a pharmacological investigation. Neuropharmacology, 1997, 36(10), $1417-$ 1424. 
[101] Jones, M.G.; Lever, I.; Bingham, S.; Read, S.; McMahon, S.B.; Parsons, A. Nitric oxide potentiates response of trigeminal neurones to dural or facial stimulation in the rat. Cephalalgia, 2001, 21(6), 643-655.

[102] Towler, P.K.; Bennett, G.S.; Moore, P.K.; Brain, S.D. Neurogenic oedema and vasodilatation: effect of a selective neuronal NO inhibitor. Neuroreport, 1998, 9(7), 1513-1518.

[103] Di Marzo, V.; Blumberg, P.M.; Szallasi, A. Endovanilloid signaling in pain. Curr. Opin. Neurobiol., 2002, 12, 372-379.

[104] Matsuda, L.A.; Lolait, S.J.; Brownstein, M.J.; Young, A.C.; Bonner, T.I. Structure of a cannabinoid receptor and functional expression of the cloned cDNA. Nature, 1990, 346(6284), 561-564.

[105] Hoehe, M.R.; Caenazzo, L.; Martinez, M.M.; Hsieh, W.T.; Modi, W.S.; Gershon, E.S.; Bonner, T.I. Genetic and physical mapping of the human cannabinoid receptor gene to chromosome 6q14-q15. New Biol., 1991, 3(9), 880-885.

[106] Tsou, K.; Brown, S.; Sañudo-Peña, M.C.; Mackie, K.; Walker, J.M. Immunohistochemical distribution of cannabinoid $\mathrm{CB} 1$ receptors in the rat central nervous system. Neuroscience, 1998, 83(2), 393-411.

[107] Akerman, S.; Kaube, H.; Goadsby, P.J. Anandamide is able to inhibit trigeminal neurons using an in vivo model of trigeminovascular-mediated nociception. J. Pharmacol. Exp. Ther., 2004a, 309(1), 56-63.

[108] Zygmunt, P.M.; Petersson, J.; Andersson, D.A.; Chuang, H.; Sørgård, M.; Di Marzo, V.; Julius, D.; Högestätt, E.D. Vanilloid receptors on sensory nerves mediate the vasodilator action of anandamide. Nature, 1999, 400(6743), 452-457.

[109] Akerman, S.; Kaube, H.; Goadsby, P.J. Anandamide acts as a vasodilator of dural blood vessels in vivo by activating TRPV1 receptors. Br. J. Pharmacol., 2004b, 142(8), 1354-1360.

[110] Cutrer, F.M., Mitsikostas, D.D.; Ayata, G.; Sanchez del Rio, M. Attenuation by butalbital of capsaicin-induced c-fos-like immunoreactivity in trigeminal nucleus caudalis. Headache, 1999, $39(10), 697-704$.

[111] Jancsó, G. Intracisternal capsaicin: selective degeneration of chemosensitive primary sensory afferents in the adult rat. Neurosci. Lett., 1981, 27(1), 41-45.

[112] Gamse, R.; Jancsó, G.; Király, E. Intracisternal capsaicin: a novel approach for studying nociceptive sensory neurons. In: Neurogenic Inflammation and Antidromic vasodilatation; Chahl, L.A.; Szolcsányi, J.; Lembeck, F. Eds.; Akadémiai Kiadó: Budapest, 1984, pp. 93-110.

[113] Kwon, Y.B.; Jeong, Y.C.; Kwon, J.K.; Son, J.S.; Kim, K.W. The antinociceptive effect of sigma-1 receptor antagonist, BD1047, in a capsaicin induced headache model in rats. Korean J. Physiol. Pharmacol., 2009, 13(6), 425-429.

[114] Mitsikostas, D.D.; Sanchez del Rio, M. Receptor systems mediating c-fos expression within trigeminal nucleus caudalis in animal models of migraine. Brain Res. Brain Res. Rev., 2001, 35(1), 2035 .

[115] Ter Horst, G.J.; Meijler, W.J.; Korf, J.; Kemper, R.H. Trigeminal nociception-induced cerebral Fos expression in the conscious rat. Cephalalgia, 2001, 21(10), 963-975.

[116] Arulmani, U.; Gupta, S.; VanDenBrink, A.M.; Centurión, D.; Villalón, C.M.; Saxena, P.R. Experimental migraine models and their relevance in migraine therapy. Cephalalgia, 2006, 26, 642-659.

[117] Eikermann-Haerter, K.; Moskowitz, M.A. Animal models of migraine headache and aura. Curr. Opin. Neurol., 2008, 21, 294-300.

[118] Jancsó, G.; Kiraly, E.; Jancsó-Gábor, A. Pharmacologically induced selective degeneration of chemosensitive primary sensory neurones. Nature, 1977, 270, 741-743.

[119] Jancsó, G.; Király, E.; Such, G.; Joó, F.; Nagy, A. Neurotoxic effect of capsaicin in mammals. Acta Physiol. Hung., 1987, 69, 295-313.

[120] Edvinsson, L.; Alm, R.; Shaw, D.; Rutledge, R.Z.; Koblan, K.S.; Longmore, J.; Kane, S.A. Effect of the CGRP receptor antagonist BIBN4096BS in human cerebral, coronary and omental arteries and in SK-N-MC cells. Eur. J. Pharmacol., 2002, 434(1-2), 49-53.

[121] Olesen, J.; Diener, H.C.; Husstedt, I.W.; Goadsby, P.J.; Hall, D.; Meier, U.; Pollentier, S.; Lesko, L.M.; BIBN 4096 BS Clinical Proof of Concept Study Group. Calcitonin gene-related peptide receptor antagonist BIBN $4096 \mathrm{BS}$ for the acute treatment of migraine. N. Engl. J. Med., 2004, 350(11), 1104-1110.

[122] Lambert, G.A.; Davis, J.B.; Appleby, J.M.; Chizh, B.A.; Hoskin, K.L.; Zagami, A.S. The effects of the TRPV1 receptor antagonist
SB-705498 on trigeminovascular sensitisation and neurotransmission. N-S. Arch. Pharmacol., 2009, 380(4), 311-325.

[123] Tohda, C.; Sasaki, M.; Konemura, T.; Sasamura, T.; Itoh, M.; Kuraishi, Y. Axonal transport of VR1 capsaicin receptor mRNA in primary afferents and its participation in inflammation-induced increase in capsaicin sensitivity. Neurochem., 2001, 76(6), 16281635.

[124] Amaya, F.; Oh-hashi, K.; Naruse, Y.; Iijima, N.; Ueda, M.; Shimosato, G.; Tominaga, M.; Tanaka, Y.; Tanaka, M. Local inflammation increases vanilloid receptor 1 expression within distinct subgroups of DRG neurons. Brain Res., 2003, 963(1-2), 190-196.

[125] Rami, H.K.; Thompson, M.; Stemp, G.; Fell, S.; Jerman, J.C.; Stevens, A.J.; Smart, D.; Sargent, B.; Sanderson, D.; Randall, A.D.; Gunthorpe, M.J.; Davis, J.B. Discovery of SB-705498: a potent, selective and orally bioavailable TRPV1 antagonist suitable for clinical development. Bioorg. Med. Chem. Lett., 2006, 16(12), 32873291.

[126] Hajós, M.; Obál, F. Jr.; Jancsó, G.; Obál, F. The capsaicin sensitivity of the preoptic region is preserved in adult rats pretreated as neonates, but lost in rats pretreated as adults. Naunyn Schmiedebergs Arch. Pharmacol., 1983, 324, 219-222.

[127] Jancsó-Gábor, A.; Szolcsányi, J.; Jancsó, N. Stimulation and desensitization of the hypothalamic heat-sensitive structures by capsaicin in rats. J. Physiol., 1970, 208, 449-459.

[128] Swanson, D.M.; Dubin, A.E.; Shah, C.; Nasser, N.; Chang, L.; Dax, S.L.; Jetter, M.; Breitenbucher, J.G.; Liu, C.; Mazur, C.; Lord, B.; Gonzales, L.; Hoey, K.; Rizzolio, M.; Bogenstaetter, M.; Codd, E.E.; Lee, D.H,; Zhang, S.P.; Chaplan, S.R.; Carruthers, N.I. Identification and biological evaluation of 4-(3-trifluoromethylpyridin2-yl)piperazine-1-carboxylic acid (5-trifluoromethylpyridin-2yl)amide, a high affinity TRPV1 (VR1) vanilloid receptor antagonist. J. Med. Chem., 2005, 48(6), 1857-1872.

[129] Gavva, N.R.; Bannon, A.W.; Surapaneni, S.; Hovland, D.N. Jr.; Lehto, S.G.; Gore, A.; Juan, T.; Deng, H.; Han, B.; Klionsky, L.; Kuang, R., Le, A.; Tamir, R., Wang, J.; Youngblood, B.; Zhu, D.; Norman, M.H., Magal, E., Treanor, J.J., Louis, J.C. The vanilloid receptor TRPV1 is tonically activated in vivo and involved in body temperature regulation. J. Neurosci., 2007b, 27(13), 3366-3374.

[130] Gavva, N.R.; Bannon, A.W.; Hovland, D.N. Jr.; Lehto, S.G., Klionsky, L.; Surapaneni, S., Immke, D.C.; Henley, C.; Arik, L.; Bak, A.; Davis, J.; Ernst, N.; Hever, G.; Kuang, R.; Shi, L.; Tamir, R.; Wang, J.; Wang, W.; Zajic, G.; Zhu, D.; Norman, M.H.; Louis, J.C.; Magal, E.; Treanor, J.J. Repeated administration of vanilloid receptor TRPV1 antagonists attenuates hyperthermia elicited by TRPV1 blockade. J. Pharmacol. Exp. Ther., 2007a, 323(1), 128137.

[131] Sicuteri, F.; Fusco, B.M.; Marabini, S.; Campagnolo, V.; Maggi, C.A.; Geppetti, P.; Fanciullacci, M. Beneficial effect of capsaicin application to the nasal mucosa in cluster headache. Clin. J. Pain., 1989, 5, 49-53.

[132] Marks, D.R.; Rapoport, A.; Padla, D.; Weeks, R.; Rosum, R.; Sheftell, F.; Arrowsmith, F. A double-blind placebo-controlled trial of intranasal capsaicin for cluster headache. Cephalalgia., 1993, 13, 114-116.

[133] Fusco, B.; Fiore, G.; Gallo, F.; Martelletti, P.; Giacovazzo, M. "Capsaicin-sensitive" sensory neurons in cluster headache: pathophysiological aspects and therapeutic indication. Headache, 1994, 34, 132-137.

[134] Bevan, S.J.; Docherty, R.J. Cellular mechanisms of the action of capsaicin. In: Capsaicin in the Study of Pain; Wood, J Ed.; Academic Press: London, 1993; pp. 27-44.

[135] Diamond, S.; Freitag, F.; Phillips, S.B.; Bernstein, J.E., Saper, J.R. Intranasal civamide for the acute treatment of migraine headache. Cephalalgia, 2000, 20(6), 597-602.

[136] Saper, J.R.; Klapper, J.; Mathew, N.T.; Rapoport, A.; Phillips, S.B.; Bernstein, J.E. Intranasal civamide for the treatment of episodic cluster headaches. Arch. Neurol., 2002, 59(6), 990-994.

[137] Buzzi, M.G.; Dimitriadou, V.; Theoharides, T.C.; Moskowitz, M.A. 5-Hydroxytryptamine receptor agonists for the abortive treatment of vascular headaches block mast cell, endothelial and platelet activation within the rat dura mater after trigeminal stimulation. Brain Res., 1992, 583(1-2), 137-149.

[138] Fuder, H.; Selbach, M. Characterization of sensory neurotransmission and its inhibition via alpha $2 \mathrm{~B}$-adrenoceptors and via nonalpha 2-receptors in rabbit iris. N-S. Arch. Pharmacol., 1993, 347(4), 394-401. 
[139] Longmore, J.; Shaw, D.; Smith, D.; Hopkins, R.; McAllister, G.; Pickard, J.D.; Sirinathsinghji, D.J.; Butler, A.J.; Hill, R.G. Differential distribution of 5HT1D- and 5HT1B-immunoreactivity within the human trigemino-cerebrovascular system: implications for the discovery of new antimigraine drugs. Cephalalgia, 1997, 17(8), 833-842.

[140] Goadsby, P.J.; Classey, J.D. Evidence for serotonin (5-HT)1B, 5HT1D and 5-HT1F receptor inhibitory effects on trigeminal neurons with craniovascular input. Neuroscience, 2003, 122(2), 491498.

[141] Kaumann, A.J.; Parsons, A.A.; Brown, A.M. Human arterial constrictor serotonin receptors. Cardiovasc. Res., 1993, 27(12), 20942103.

[142] Ullmer, C.; Schmuck, K.; Kalkman, H.O.; Lübbert, H. Expression of serotonin receptor mRNAs in blood vessels. FEBS Lett., 1995, 370(3), 215-221.

[143] Bouchelet, I.; Cohen, Z.; Case, B.; Séguéla, P.; Hamel, E. Differential expression of sumatriptan-sensitive 5-hydroxytryptamine receptors in human trigeminal ganglia and cerebral blood vessels. Mol. Pharmacol., 1996, 50(2), 219-223.

[144] Waeber, C.; Moskowitz, M.A. [3H]sumatriptan labels both 5HT1D and 5-HT1F receptor binding sites in the guinea pig brain: an autoradiographic study. N-S. Arch. Pharmacol., 1995, 352(3), 263-275.

[145] Potrebic, S.; Ahn, A.H.; Skinner, K.; Fields, H.L.; Basbaum, A.I. Peptidergic nociceptors of both trigeminal and dorsal root ganglia express serotonin 1D receptors: implications for the selective antimigraine action of triptans. J. Neurosci., 2003, 23(34), 1098810997.

[146] Salvatore, C.A.; Hershey, J.C.; Corcoran, H.A.; Fay, J.F.; Johnston, V.K.; Moore, E.L.; Mosser, S.D.; Burgey, C.S.; Paone, D.V.; Shaw, A.W.; Graham, S.L., Vacca, J.P., Williams, T.M., Koblan, K.S., Kane, S.A. Pharmacological characterization of MK-0974 [N-[(3R,6S)-6-(2,3-difluorophenyl)-2-oxo-1-(2,2,2trifluoroethyl)azepan-3-yl]-4-(2-oxo-2,3-dihydro-1H-imidazo[4,5b]pyridin-1-yl)piperidine-1-carboxamide], a potent and orally active calcitonin gene-related peptide receptor antagonist for the treatment of migraine. J. Pharmacol. Exp. Ther., 2008, 324(2), 416-421.

[147] Ho, T.W.; Ferrari, M.D.; Dodick, D.W.; Galet, V.; Kost, J.; Fan, X.; Leibensperger, H.; Froman, S.; Assaid, C.; Lines, C.; Koppen, H.; Winner, P.K. Efficacy and tolerability of MK-0974 (telcagepant), a new oral antagonist of calcitonin gene-related peptide receptor, compared with zolmitriptan for acute migraine: a randomised, placebo-controlled, parallel-treatment trial. Lancet, 2008a 372(9656), 2115-2123

[148] Ho, T.W.; Mannix, L.K.; Fan, X.; Assaid, C.; Furtek, C.; Jones, C.J.; Lines, C.R.; Rapoport, A.M.; MK-0974 Protocol 004 study group. Randomized controlled trial of an oral CGRP receptor antagonist, MK-0974, in acute treatment of migraine. Neurology, 2008b, 70(16), 1304-1312. 